\title{
A comparison of four different models of acute respiratory distress syndrome in sheep
}

Monique Engel ${ }^{1^{*}}$ D, Relana M. E. Nowacki ${ }^{1}$, Elly M. Jonker ${ }^{1}$, Daan Ophelders ${ }^{1}$, Maria Nikiforou ${ }^{1}$, Nico Kloosterboer ${ }^{1}$, Luc J. I. Zimmermann', Dick A. van Waardenburg ${ }^{2}$ and Boris W. Kramer ${ }^{1,3}$

\begin{abstract}
Background: Acute respiratory distress syndrome (ARDS) can have various causes. The study objective was to investigate whether different pathophysiologic models of ARDS would show different respiratory, cardiovascular and inflammatory outcomes.

Methods: We performed a prospective, randomized study in 27 ventilated ewes inducing ARDS using three different techniques to mimic the pulmonary causes of ARDS (ARDSp): warm saline lavage $(n=6)$, intratracheal hydrochloric acid $(\mathrm{HCl} ; n=6)$, intratracheal albumin $(n=10)$, and one technique to mimic an extrapulmonary cause of ARDS (ARDSexp): intravenous lipopolysaccharide (LPS iv; $n=5)$. ARDS was defined when $\mathrm{PaO}_{2}$ was $<15 \mathrm{kPa}(112$ $\mathrm{mmHg}$ ) when ventilated with PEEP $10 \mathrm{~cm} \mathrm{H}_{2} \mathrm{O}$ and $\mathrm{FiO}_{2}=1.0$. The effects on gas exchange were investigated by calculating the oxygenation index $(\mathrm{OI})$ and the ventilation efficacy index (VEI) every 30 min for a period of $4 \mathrm{~h}$. Post mortem lung lavage was performed to obtain broncho-alveolar lavage fluid (BALF) to assess lung injury and inflammation. Lung injury and inflammation were assessed by measuring the total number and differentiation of leukocytes, the concentration of protein and disaturated phospholipids, and interleukine- 6 and -8 in the BALF. Histology of the lung was evaluated by measuring the mean alveolar size, alveolar wall thickness and the lung injury score system by Matute-Bello et al., as markers of lung injury. The concentration of interleukin-6 was determined in plasma, as a marker of systematic inflammation.

Results: The OI and VEl were most affected in the LPS iv group and thereafter the $\mathrm{HCl}$ group, after meeting the ARDS criteria. Diastolic blood pressure was lowest in the LPS iv group. There were no significant differences found in the total number and differentiation of leukocytes, the concentration of protein and disaturated phospholipids, or interleukin-8 in the BALF, histology of the lung and the lung injury score. IL-6 in BALF and plasma was highest in the LPS iv group, but no significant differences were found between the other groups. It took a significantly longer period of time to meet the ARDS criteria in the LPS iv group.

(Continued on next page)
\end{abstract}

\footnotetext{
* Correspondence: M.Engel@mumc.nl

'Department of Pediatrics, School for Oncology and Developmental Biology

- GROW, Maastricht University Medical Centre (MUMC+), P. Debyelaan 25,

PO Box 5800, NL-6202, AZ, Maastricht, The Netherlands

Full list of author information is available at the end of the article
}

\section{$\triangle B M C$}

(c) The Author(s). 2020 Open Access This article is licensed under a Creative Commons Attribution 4.0 International License, which permits use, sharing, adaptation, distribution and reproduction in any medium or format, as long as you give appropriate credit to the original author(s) and the source, provide a link to the Creative Commons licence, and indicate if changes were made. The images or other third party material in this article are included in the article's Creative Commons licence, unless indicated otherwise in a credit line to the material. If material is not included in the article's Creative Commons licence and your intended use is not permitted by statutory regulation or exceeds the permitted use, you will need to obtain permission directly from the copyright holder. To view a copy of this licence, visit http://creativecommons.org/licenses/by/4.0/ The Creative Commons Public Domain Dedication waiver (http://creativecommons.org/publicdomain/zero/1.0/) applies to the data made available in this article, unless otherwise stated in a credit line to the data. 
(Continued from previous page)

Conclusions: The LPS model caused the most severe pulmonary and cardiovascular insufficiency. Surprisingly, there were limited significant differences in lung injury and inflammatory markers, despite the different pathophysiological models, when the clinical definition of ARDS was applied.

Keywords: ARDS, Acute respiratory distress syndrome, Pulmonary, Extra-pulmonary, Lung injury, Sheep

\section{Introduction}

Acute respiratory distress syndrome (ARDS) is characterized by the acute onset of bilateral pulmonary infiltrates and severe hypoxemia with respiratory failure, in the absence of cardiogenic pulmonary edema [1]. The underlying causes of ARDS are various but can be generally divided in two broad categories: a direct pulmonary insult, like a pulmonary infection, or an indirect insult on the lungs, such as sepsis [2-9]. If the etiology of ARDS is restricted to damage or disease of the lung itself, it is called pulmonary ARDS (ARDSp) [2-9]. If the etiology of ARDS occurs outside the lung, as in a systematic inflammatory response, it is called extra-pulmonary ARDS (ARDSexp) [2-9]. Both types of ARDS are characterized by damage of the alveolar-capillary barrier due to diffuse alveolar damage and capillary endothelial injury [4-6]. Studies in humans have reported different pathophysiology, respiratory mechanics and morphological properties between ARDSp and ARDSexp [3-8]. In the early stages of ARDSp, damage to the alveolar cells is prevalent, whereas in ARDSexp, interstitial edema is the first indication of damage [5]. Furthermore, in bronchoalveolar lung fluid (BALF), the interleukin-8 (IL-8) concentration, a pro-inflammatory cytokine of systemic inflammation and neutrophil recruitment, is significantly higher in ARDSp than in ARDSexp patients [9].

Different animal models have been used to study the pathophysiology of pulmonary and extra-pulmonary ARDS [10-14]. However, no single animal model mimics all of the clinical features of ARDS seen in humans [4]. We therefore performed a comparative study in adult sheep, in which ARDS was induced using four different insults. ARDSp was induced by lung lavage, intratracheal administration of albu$\min 20 \%$, or hydrochloric acid [10, 12-14]. We chose the lung lavage and hydrochloric acid insult as ARDSp models because these are proven models for ARDSp in literature [10, 12-14]. The intratracheal albumin $20 \%$ model has been published in neonates as a rescue therapy in meconium aspiration syndrome limiting the effect on the lung and reducing the increase of Interleukin-8 $[15,16]$. But in the pathophysiology of ARDS, protein influx, like albumin, in the alveoli induces serious impairment of alveolar surfactant activity [17]. These data seem to be contradictive. Therefore, we wanted to investigate the effect of this insult on respiratory, cardiovascular and inflammatory outcomes in a naive adult model. ARDSexp was induced by intravenously administering lipopolysaccharide (LPS iv) from E.coli [10, 12, 14].
The different insults were chosen to reflect the multiple pathogeneses of ARDS [10-14]. When ARDSp was induced by lung lavage or intratracheal administration of albumin $20 \%$, the washout and/or inactivation of surfactant was considered to be the most important mechanism of injury [10, $12,14]$. This was in contrast to the intratracheal administration of hydrochloric acid where a direct alveolar damage was induced $[10,12,13]$. The intravenous LPS administration induced a systemic inflammation with secondary endothelial injury $[10,12,14]$. We hypothesized that there would be differences in pulmonary, cardiovascular and inflammatory outcomes between the ARDSp and ARDSexp group, due to the different pathophysiology. We therefore assessed oxygenation index (OI) and ventilation efficacy index (VEI) as markers for gas exchange; inflammatory cells, and differentiation in broncho-alveolar lavage fluid (BALF) and interleukin-6 (IL-6) and interleukin-8 (IL-8) in BALF as markers for alveolar inflammation; total protein in BALF as a marker for lung injury and edema; disaturated phospholipids (DSPL) in BALF as a marker for surfactant pool size; lung histology as a marker for atelectasis and overinflation; the lung injury score by Matute-Bello et al. as a marker for lung injury and IL-6 in plasma as markers of systemic inflammation. We studied the animals for $4 \mathrm{~h}$ after the predefined clinical onset of ARDS.

\section{Methods}

\section{Experimental protocol}

We conducted a randomized, prospective study in sheep, using four different models of ARDS. The Animal Ethical Committee of the Maastricht University Medical Centre (MUMC+), the Netherlands, approved the study.

Pulmonary causes of ARDS were mimicked using lung lavage, intratracheal administrating of albumin $20 \%$, or hydrochloric acid [10-14]. Extra-pulmonary ARDS was induced by administrating intravenous lipopolysaccharide (LPS) from E.coli $[10,12,14]$.

Twenty-seven adult Texel ewes, age 1 year plus minus 3 months, were intravenously anesthetized with thiopental, intubated, and mechanically ventilated with a pressure-controlled ventilation (PCV) (Servo 900 ventilator, Siemens, Germany) $[18,19]$. The ventilator settings consisted of a peak pressure to maintain a tidal volume (Vt) of $6-8 \mathrm{~mL} / \mathrm{kg}$, a respiratory rate of 15 breaths per minute, an inspiratory time of $50 \%$, a positive end expiratory pressure (PEEP) of $10 \mathrm{~cm} \mathrm{H}_{2} \mathrm{O}$, and a fraction of 
inspired oxygen $\left(\mathrm{FiO}_{2}\right)$ of $1.0[18,19]$. A central venous and arterial catheter were inserted. The sheep were sedated during the experiment with intravenously administered midazolam $(0.2 \mathrm{mg} / \mathrm{kg} / \mathrm{h})$, ketamine $(8 \mathrm{mg} / \mathrm{kg} / \mathrm{h})$, and paralyzed with repeated boluses of pancuronium $(0.1 \mathrm{mg} / \mathrm{kg})$ if needed $[18,19]$. The sheep were randomly assigned to four different groups. The sheep were selected by the animal technician, who was not involved in the experiment and the insult was assigned according the date of the research. The groups varied according to the insult by which the ARDS was induced:

1. Warm saline broncho-alveolar lavage $(n=6)[10,12,14]$. In this group, a broncho-alveolar lavage was performed using $500 \mathrm{~mL}$ per kilogram body weight of sterile $0.9 \%$ $\mathrm{NaCl}$ at $39^{\circ} \mathrm{C}$. This procedure was repeated every 15 min until the arterial oxygen pressure $\left(\mathrm{PaO}_{2}\right)$ had decreased to $15 \mathrm{kPa}(112 \mathrm{mmHg})$ at $\mathrm{PEEP}$ of $10 \mathrm{~cm} \mathrm{H}_{2} \mathrm{O}$ and $\mathrm{FiO}_{2}$ of 1.0.

2. Intratracheal albumin $20 \%(n=10)[15,16]$. In this group, $250 \mathrm{mg}$ albumin $20 \%$ per kilogram body weight was administered intratracheally through a small tube that was temporarily placed in the endotracheal tube.

3. Intratracheal hydrochloric acid $(\mathrm{HCl})(n=6)$ $[10,12-14]$. This group was given $\mathrm{HCl} 0.5 \mathrm{~N}$ $1.5 \mathrm{~mL}$ per kilogram body weight intratracheally through a small tube that was temporarily inserted in the endotracheal tube and advanced to the carina before injection.

4. Intravenous lipopolysaccharide (LPS iv) $(n=5)$ $[10,12,14]$. This group received $75 \mu \mathrm{g}$ per kilogram body weight LPS of E. coli serotype 0.5B55 (Sigma Aldrich, Amsterdam The Netherlands) intravenously every hour over the course of the experiment, until the criteria of ARDS had been met.

ARDS was pre-defined as $\mathrm{PaO}_{2}<15 \mathrm{kPa}(112 \mathrm{mmHg})$ when ventilated with PEEP $10 \mathrm{~cm} \mathrm{H}_{2} \mathrm{O}$ and $\mathrm{FiO}_{2} 1.0$ [15, 16]. The length of time that passed between the initiation of lung injury and meeting the ARDS criteria was recorded. In order to make a comparison between the groups possible, the time point at which the animals fulfilled the criteria of ARDS was taken as the starting point of the 4-h study period $(\mathrm{T}=0)$.

Arterial analyses for gas exchange were performed at baseline and every $30 \mathrm{~min}$ thereafter for the duration of the experiment. Cardio-respiratory settings were recorded every $30 \mathrm{~min}$. Plasma from blood samples were collected every $30 \mathrm{~min}$, spun down and stored at $-80^{\circ} \mathrm{C}$. After 4 hours, the animals were euthanized by an intravenous injection of thiopental $[18,19]$. Thoracotomy was performed and the lungs were removed. The left lung was lavaged with $0.9 \% \mathrm{NaCl}$ and broncho-alveolar lavage fluid (BALF) was collected and analyzed for differential cell counts. The remaining volume was aliquoted and frozen for measurement of total protein, disaturated phospholipids (DSPL), and interleukin-6 (IL6) and interleukin- 8 (IL-8) at $-80^{\circ} \mathrm{C}$. The inflated right lower lobe of the lung was fixed in buffered $4 \%$ formaldehyde and samples were taken for histology and lung injury score.

\section{Oxygenation index $(\mathrm{OI})$ and ventilation efficacy index (VEI)}

As markers of gas exchange, OI and VEI were calculated from the cardio-respiratory parameters and blood gas analyses before and after lavage, and every $30 \mathrm{~min}$ during the 4-h study period [18, 19]. OI was calculated by multiplying the oxygen fraction times mean airway pressure $\left(\mathrm{cm} \mathrm{H}_{2} \mathrm{O}\right)$ and dividing this by $\mathrm{PaO}_{2}(\mathrm{~mm} \mathrm{Hg})$ $\left(\left(\mathrm{FiO}_{2} \times \mathrm{MAP}\right) / \mathrm{PaO}_{2}\right)$. The VEI was calculated by dividing 3800 by the pressure difference between the PEEP and peak pressure (in $\mathrm{cm} \mathrm{H}_{2} \mathrm{O}$ ) times the respiratory rate (breaths/min) times the $\mathrm{PaCO}_{2}(\mathrm{~mm} \mathrm{Hg})$ (3800/ (PIP-PEEP) $x \mathrm{RR} \times \mathrm{PaCO}_{2}$ ).

\section{Inflammatory cell count and differentiation in BALF}

A cell count was performed after mixing the BALF with 0.4\% trypan blue stain, (Gibco Invitrogen Corporation, California, USA) using the modified Neubauer Hemocytometer (Hirschmann EM Techcolor) [20]. A May-Grünwald-Giemsa staining was performed on the BALF smears, in which all neutrophils, lymphocytes and monocytes were counted in 200 cells. For each cell type, the total number of cells was calculated per kilogram body weight [20]. This was used as marker for inflammation.

\section{Total protein in BALF}

The protein concentration of the BALF was measured using the Micro BCA Protein Assay Reagent Kit (Thermo Fisher Scientific Inc., Illinois, USA), according to the manufacturer's instructions. The microtiter plate was read at a wavelength of $562 \mathrm{~nm}$. All photospectroanalyses were done using Multiskan Spectrum hardware and SkanIt RE for MSS 2.2 software (Thermo Electron Corporation, Massachusetts, USA). Translation of optical densities into concentrations was carried out using GraphPad Prism 5 software (GraphPad Software, California, USA) [21, 22]. Total protein in BALF was used as a marker for lung injury and interstitial edema.

\section{Disaturated phospholipids in BALF}

The DSPL in BALF was measured after $10 \mathrm{~min}$ of centrifugation of the BALF at $300 \times \mathrm{g}$ and $4{ }^{\circ} \mathrm{C}$, and $1 \mathrm{~mL}$ of the 
Table 1 The respiratory and circulatory parameters of the four groups before ARDS was induced and after the criteria for ARDS had been met (mean $\pm \mathrm{SD})$

\begin{tabular}{|c|c|c|c|c|c|c|c|}
\hline & $\mathrm{N}$ & PIP & $\mathrm{Ol}$ & VEI & Heart rate & Systolic blood & Diastolic blood \\
\hline & & $(\mathrm{cm} \mathrm{H} 2 \mathrm{O})$ & & & (beats/min) & pressure $(\mathrm{mmHg})$ & pressure $(\mathrm{mmHg})$ \\
\hline Lavage pre & 6 & $21 \pm 2$ & $3.2 \pm 0.5$ & $0.44 \pm 0.07$ & $117 \pm 17$ & $142 \pm 6$ & $123 \pm 5$ \\
\hline Albumin 20\% pre & 10 & $18 \pm 2$ & $2.9 \pm 0.5$ & $0.53 \pm 0.11$ & $118 \pm 28$ & $133 \pm 23$ & $113 \pm 20$ \\
\hline $\mathrm{HCl}$ pre & 6 & $20 \pm 3$ & $3.6 \pm 0.6$ & $0.47 \pm 0.9$ & $99 \pm 17$ & $125 \pm 20$ & $106 \pm 18$ \\
\hline LPS iv pre & 5 & $20 \pm 3$ & $3.4 \pm 0.7$ & $0.43 \pm 0.09$ & $112 \pm 21$ & $125 \pm 10$ & $108 \pm 8$ \\
\hline$p<0.05$ pre & & no & no & no & no & no & no \\
\hline Lavage post & 6 & $34 \pm 3$ & $45.1 \pm 38.7$ & $0.17 \pm 0.05$ & $112 \pm 13$ & $95 \pm 16$ & $63 \pm 18$ \\
\hline Albumin $20 \%$ post & 10 & $36 \pm 6$ & $37.4 \pm 12$ & $0.16 \pm 0.07$ & $130 \pm 29$ & $119 \pm 17$ & $99 \pm 19$ \\
\hline $\mathrm{HCl}$ post & 6 & $38 \pm 4$ & $36.8 \pm 7.8$ & $0.18 \pm 0.03$ & $108 \pm 31$ & $116 \pm 6$ & $99 \pm 10$ \\
\hline LPS iv post & 5 & $36 \pm 10$ & $62.5 \pm 17.7$ & $0.11 \pm 0.01$ & $127 \pm 14$ & $106 \pm 21$ & $88 \pm 22$ \\
\hline$p<0.05$ post & & no & no & no & no & no & yes \\
\hline
\end{tabular}

supernatant BALF was evaporated overnight at $60{ }^{\circ} \mathrm{C}$ under continuous nitrogen gas flow. The dry BALF was dissolved in a mixture of carbon tetrachloride and osmium tetroxide and disaturated phospholipids were isolated according to Mason et al. [23]. The DSPL were dissolved in chloroform and quantified according to Stewart, with some minor modifications, as described by Been et al. $[24,25]$. The DSPL in BALF was taken as a marker for the surfactant pool size.

\section{Interleukin (IL)-6 and IL-8 in BALF; IL-6 in plasma}

In the BALF and in the plasma, respectively, the concentration of IL- 6 and IL- 8 were quantified with a sheepspecific sandwich ELISA $[21,26]$ and used as markers of lung and systemic inflammation.

\section{Histology and lung injury score}

We evaluated lung injury using histology of the right lower lobe of the lung, by measuring the mean alveolar size (MAS), alveolar wall thickness (AWT) and the lung injury score system by Matute-Bello et al. [27]. MAS was used as a marker of atelectasis and overinflation, while AWT was used as a marker for edema. The lung injury score system scored neutrophils in the alveolar space (A), neutrophils in the interstitial space (B), hyaline membranes $(\mathrm{C})$, proteinaceous debris filling the airspace (D) and alveolar septal thickening (E). Every item was given a score between 0 to 2 . The score was calculated by: $((20 \times \mathrm{A})+(14 \times \mathrm{B})+(7 \times \mathrm{C})+(7 \times \mathrm{D})+(2 \times \mathrm{E})) /$ number of fields $\times 100$, leading to a score between zero (no lung injury) and one (severe lung injury) [27]. Samples of the lung were imbedded in paraffin, cut into $4 \mu \mathrm{m}$ slices, deparaffinized in an ethanol series, stained with hematoxylin and eosin, dehydrated, and cover slipped. To measure MAS and AWT per location, 10 representative microscopic images were made with a 10fold magnification using the Leica microscope (Axioskop 4.0; Zeiss) and Leica Qwin Pro version 3.4.0 software (Leica Microsystems, Mannheim, Germany). All images were uploaded and analyzed by Matlab 6.0 software

Table 2 The characteristics and parameters at the end of the experiment, $4 \mathrm{~h}$ after the criteria for ARDS had been met (mean \pm SD)

\begin{tabular}{|c|c|c|c|c|c|}
\hline & Lavage & Albumin $20 \%$ & $\mathrm{HCl}$ & LPS & $p<0.05$ \\
\hline $\bar{N}$ & 6 & 10 & 6 & 5 & \\
\hline Death during exp & 0 & 0 & 0 & 1 & \\
\hline Cells BALF (corr) (cells/kg) & $43.7 \pm 19.4$ & $204.7 \pm 509.2$ & $38 \pm 33.5$ & $73.2 \pm 53.5$ & no \\
\hline Neutro BALF (corr) (cells/kg) & $12.5 \pm 8.8$ & $58.4 \pm 142.2$ & $29.3 \pm 30.1$ & $8.2 \pm 7.1$ & no \\
\hline Protein BALF (corr) (mg/kg) & $60.1 \pm 41.6$ & $89.5 \pm 80.4$ & $54.4 \pm 40.8$ & $32.3 \pm 22.2$ & no \\
\hline DSPL BALF (corr) (mg/kg) & $0.087 \pm 0.061$ & $0.103 \pm 0.061$ & $0.071 \pm 0.011$ & $0.132 \pm 0.09$ & no \\
\hline IL-8 BALF (corr) (ng/kg) & $6.66 \pm 5.67$ & $4.42 \pm 5.5$ & $3.46 \pm 1.82$ & $6.95 \pm 2.5$ & no \\
\hline $\operatorname{MAS}\left(\mu \mathrm{m}^{2}\right)$ & $6782 \pm 1665$ & $7078 \pm 1694$ & $7634 \pm 3705$ & $5158 \pm 2400$ & no \\
\hline AWT $\left(\mu m^{2}\right)$ & $26.2 \pm 2.1$ & $27.8 \pm 2.2$ & $30 \pm 3.8$ & $29.4 \pm 2.7$ & no \\
\hline Lung injury score & $0.025 \pm 0.004$ & $0.023 \pm 0.003$ & $0.024 \pm 0.004$ & $0.025 \pm 0.003$ & no \\
\hline
\end{tabular}


(The Mathworks, Inc. Massachusetts, USA) to measure MAS and AWT in a blinded manner. To calculated the lung injury score 20 random high-power fields $(400 \mathrm{x}$ total magnification) were scored per animal, by a blinded researcher, and the lung injury score was calculated per animal [27].

\section{Statistical analysis}

Statistical analysis was performed using one-way ANOVA with a Bonferroni post-hoc test in Graphpad Prism. Data are presented as mean \pm SEM unless individual measurements are shown; $p<0.05$ was considered to be statistically significant.

\section{Results}

In total, 27 sheep were included in the study. ARDS was induced in all four experimental models according to the predefined criteria $(\mathrm{PaO} 2<15 \mathrm{kPa} \quad(112 \mathrm{mmHg})$, PEEP $10 \mathrm{~cm} \mathrm{H} 2 \mathrm{O}, \mathrm{FiO} 2$ 1.0). The respiratory and circulatory parameters of the four groups before ARDS was induced, and after the ARDS criteria had been met, are shown in Table 1 . There were no differences between the groups at both time points, except for the diastolic blood pressure that was lower in the lavage group after the ARDS criteria had been met. All animals - except for one in the LPS iv group - survived the 4-h study period of the experiment (Table 2).

The amount of time from the start of the experimental procedure until the pre-defined definition of ARDS had been reached was almost twice as long in the ARDSexp group as compared to the three ARDSp groups (Fig. 1).
The OI and VEI in time to reach the pre-defined definition of ARDS, which was defined as $\mathrm{T}=0 \mathrm{~h}$, in the LPS iv group, the ARDSexp group, are shown in Fig. $2 \mathrm{a}$ and $\mathrm{b}$.

\section{Oxygenation index (OI) and ventilation efficacy index (VEI) during the experiment}

The OI was significantly higher, indicating more severe impairment of oxygenation, in the LPS iv group than in the albumin $20 \%$ group (Fig. 3). The OI was also significantly higher in the LPS iv group than in the lavage group, except at $\mathrm{T}=0.5 \mathrm{~h}$. Furthermore, the $\mathrm{OI}$ was significantly higher in the LPS iv group than in the $\mathrm{HCl}$ group at $\mathrm{T}=2.5,3$ and $3.5 \mathrm{~h}$ (Fig. 3 ). The $\mathrm{OI}$ in the $\mathrm{HCl}$ group was significantly higher than in the albumin $20 \%$ group, except at $\mathrm{T}=2.5$ and $3 \mathrm{~h}$. The $\mathrm{OI}$ in the $\mathrm{HCI}$ group was also significantly higher than in the lavage group, at $\mathrm{T}=2,2.5,3.5$ and $4 \mathrm{~h}$ (Fig. 3 ).

The VEI was significantly lower, indicating a more severe impairment of ventilation, in the LPS iv group as compared to the lavage group from $\mathrm{T}=1.5 \mathrm{~h}$ onwards. The VEI in the LPS iv group was also significantly lower than in the albumin $20 \%$ group at $\mathrm{T}=2,3,3.5$ and $4 \mathrm{~h}$ (Fig. 4). Furthermore, the VEI was significantly lower in the $\mathrm{HCl}$ group compared to both the albumin 20\% group and the lavage group from $\mathrm{T}=2 \mathrm{~h}$ onwards (Fig. 4).

The OI and VEI showed progressive improvement in the three ARDSp groups during the 4-h of the experiment (Figs. 3 and 4). This was not the case in the LPS iv group (Figs. 3 and 4 ).

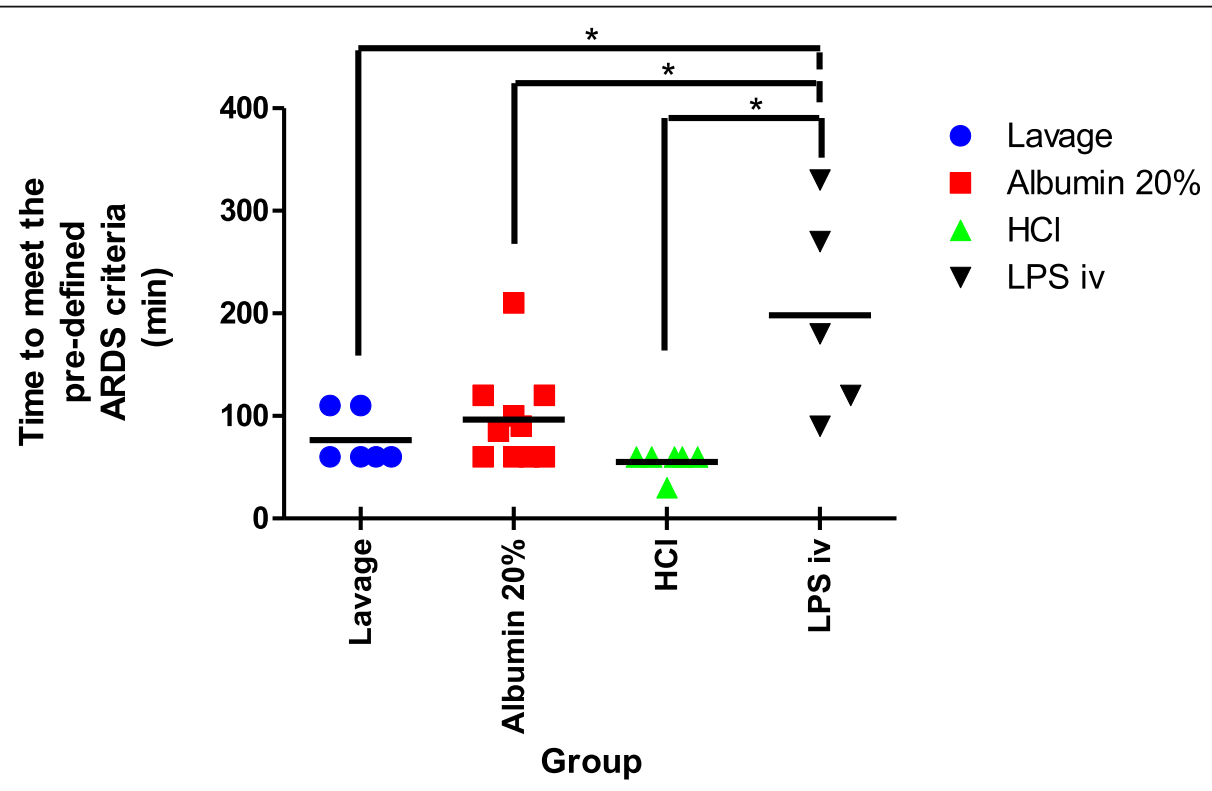

Fig. 1 The time from the start of the experimental procedure until the pre-defined definition of ARDS had been met; PaO2 < $15 \mathrm{kPa}$ when ventilated with PEEP $10 \mathrm{~cm} \mathrm{H} 2 \mathrm{O}$ and FiO2 1.0. Time taken to meet the pre-defined criteria for ARDS was significantly longer in the LPS iv group than the other three groups $(* p<0.05)$ 
A.

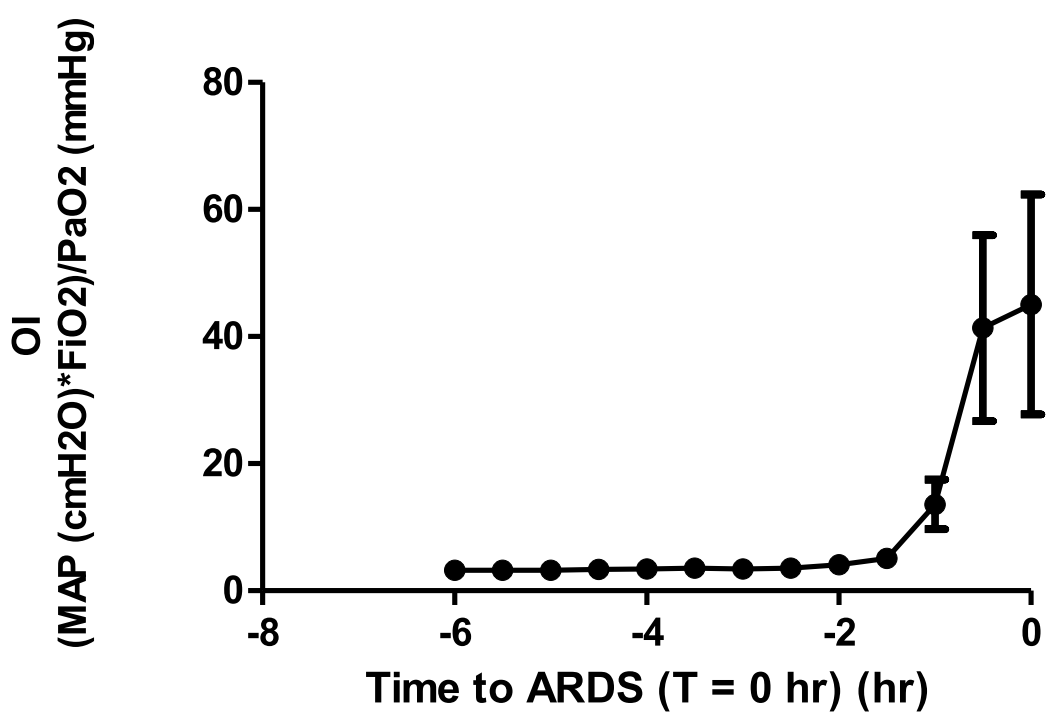

B.

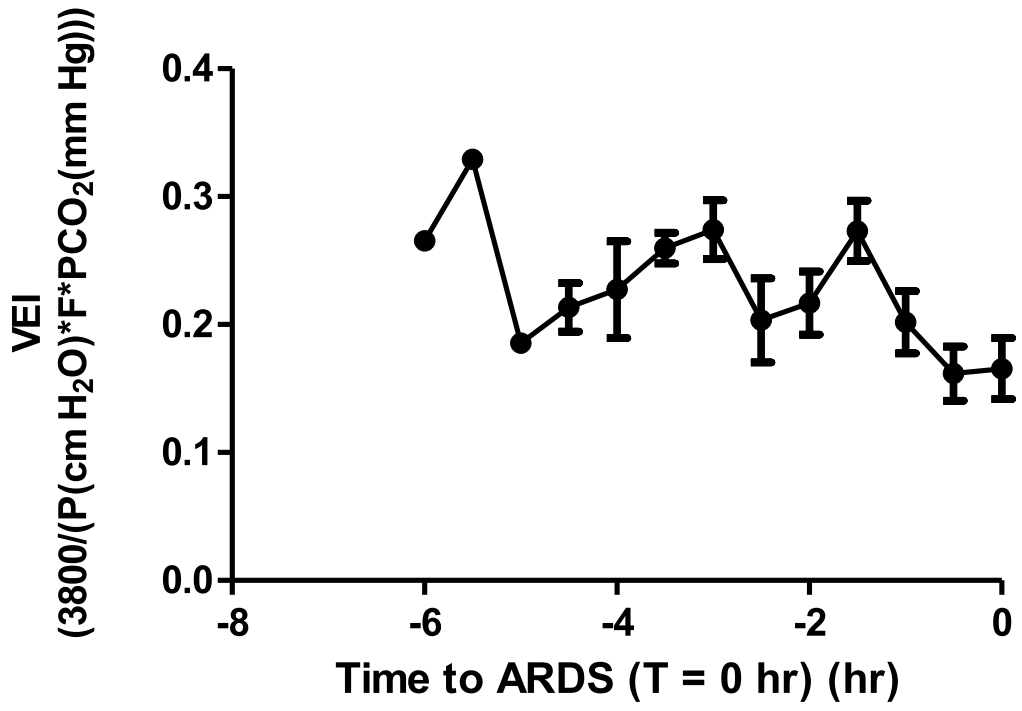

Fig. 2 The oxygenation index (OI) (2 A) and ventilation efficacy index (VEI) (2 B) in time to reach the pre-defined definition of ARDS, which is defined as $T=0 \mathrm{~h}$, in the LPS iv group, the ARDSexp group

\section{Blood pressure}

The diastolic blood pressure was significantly lower in the LPS iv group when compared to the albumin $20 \%$ group from $\mathrm{T}=1.5$ $\mathrm{h}$ onwards, except at $\mathrm{T}=3 \mathrm{~h}$. The diastolic blood pressure was also significantly lower in the LPS iv group compared to the $\mathrm{HCl}$ and lavage groups at $\mathrm{T}=1.5$ and $2 \mathrm{~h}$ (Fig. 5). The systolic blood pressure in the $\mathrm{HCl}$ group was significantly lower as compared to the albumin $20 \%$ group at $\mathrm{T}=2.5,3.5$ and $4 \mathrm{~h}$ (Fig. 5).
Cells, differentiation, total protein, disaturated phospholipids (DSPL), interleukin-6 (IL-6) and interleukin8 (IL-8) in broncho-alveolar lavage fluid (BALF), plasma, histology and lung injury score

There were no significant differences found in the total number and differentiation of leukocytes in the BALF, which we used as a marker of inflammation. The concentrations of total protein in BALF, used as a marker of 


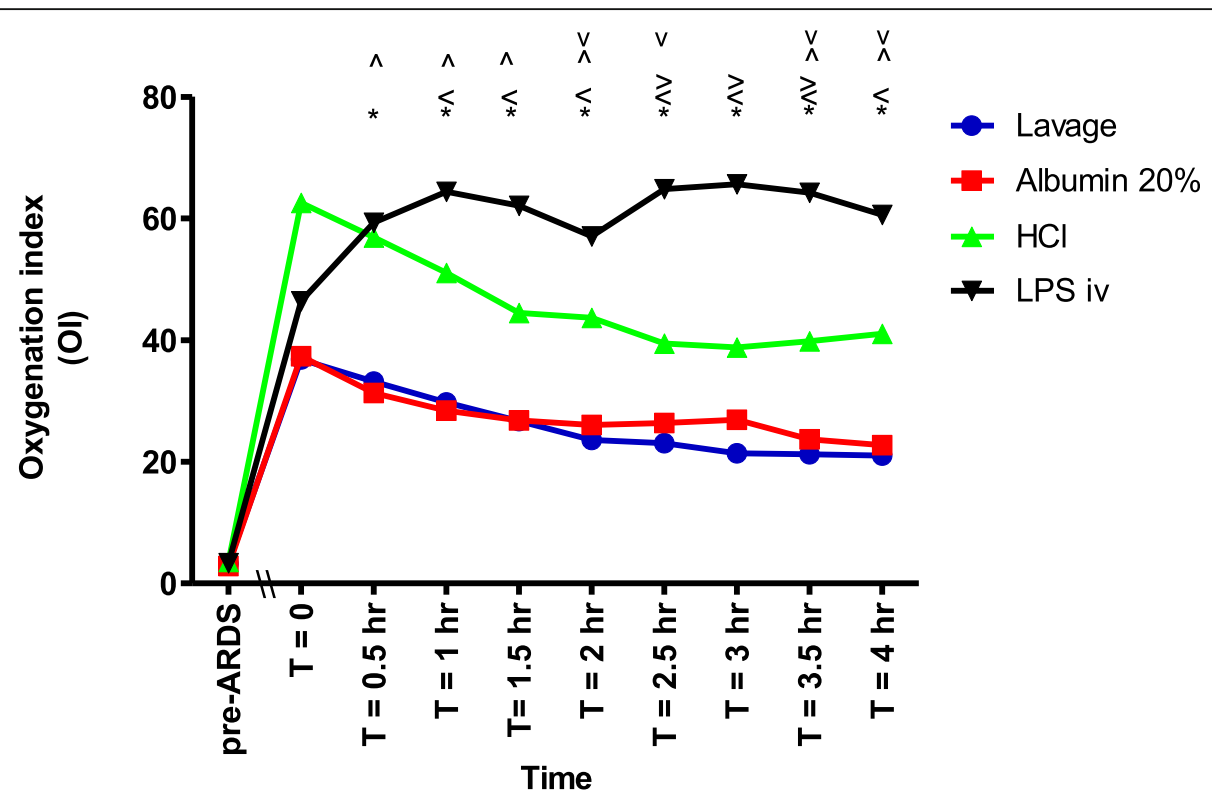

Fig. 3 The oxygenation index (OI) between the different groups at different time points during the experiment. $\left(^{*}\right)$ Ol LPS iv significantly higher than Albumin 20\% $(p<0.05)$. ( $<$ ) OI LPS iv significantly higher than lavage $(p<0.05)$. (>) OI LPS iv significantly higher than $\mathrm{HCl}(p<0.05)$. ( $)$ Ol $\mathrm{HCl}$ significantly higher than Albumin $20 \%(p<0.05)$. ( $\left(^{v}\right)$ Ol HCl significantly higher than lavage $(p<0.05)$

lung injury and edema, were not different. The surfactant pool size, assessed as DSPL in the BALF, was similar in all groups. There were also no significant differences between groups in the IL- 8 concentration in BALF (Table 2).

The IL-6 concentration in BALF was significantly higher in the LPS iv group as compared to the other three groups at $\mathrm{T}=4 \mathrm{~h}$ (Fig. 6). The IL-6 concentration in plasma was measured both at the point in time when the ARDS criteria was met, $\mathrm{T}=0 \mathrm{~h}$ (Fig. $7 \mathrm{~A}$ ), and at the end of the experiment at $\mathrm{T}=4 \mathrm{~h}$ (Fig. $7 \mathrm{~B}$ ). IL-6 concentrations did not differ between the experimental groups at the beginning of the study period $(\mathrm{T}=0 \mathrm{~h})($ Fig. $7 \mathrm{~A})$. The concentration of IL-6 in plasma was, however,

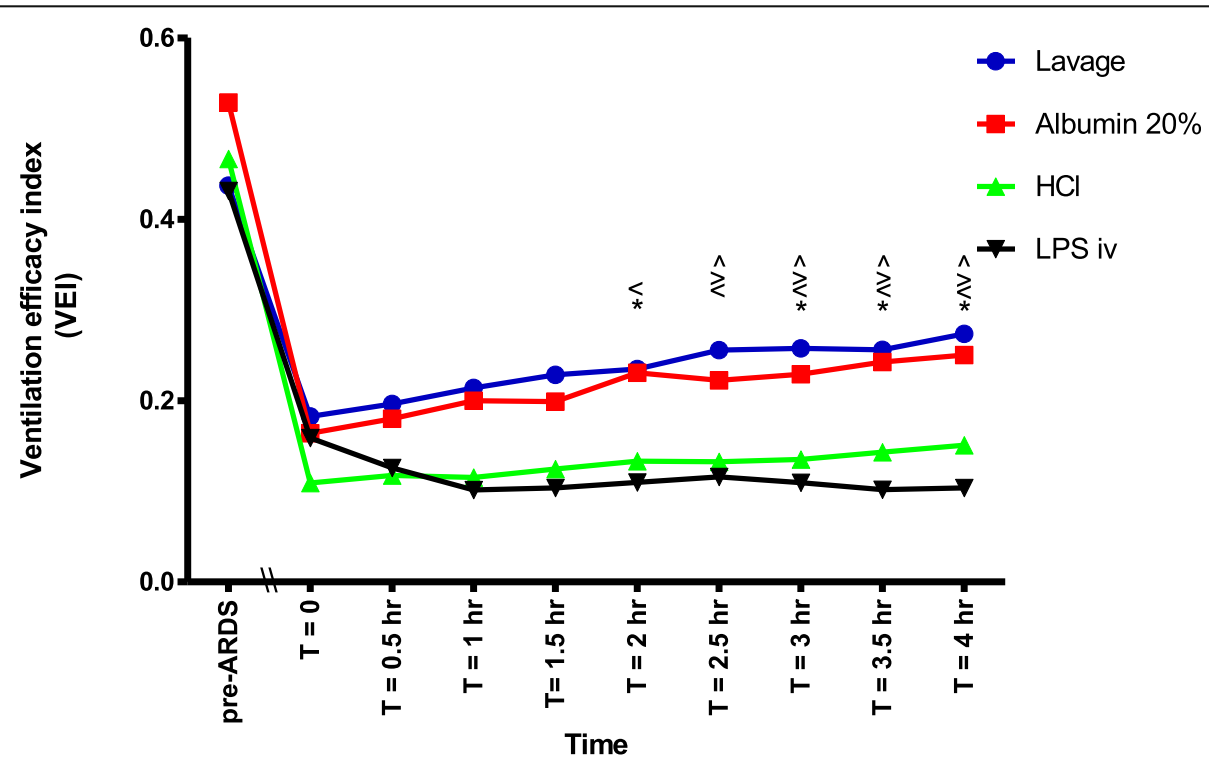

Fig. 4 The ventilation efficacy index (VEI) between the different groups at different time points during the experiment. ${ }^{*}$ ) VEI LPS iv significantly lower than Albumin 20\% $(p<0.05)$. ( $<$ ) VEI LPS iv significantly lower than lavage $(p<0.05)$. ( $>$ ) VEI HCl significantly lower than Albumin $20 \%(p<$ 0.05). ( $\wedge$ VEl HCl significantly lower than lavage $(p<0.05)$ 


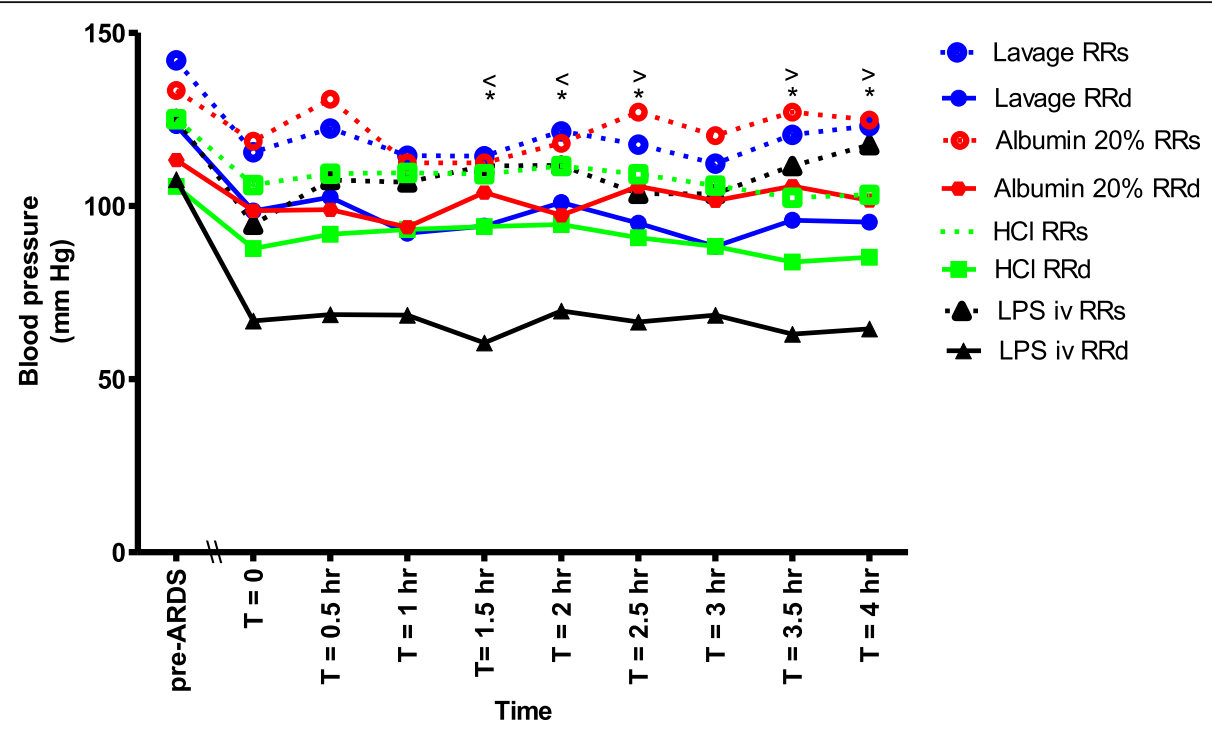

Fig. 5 The systolic (RRs) and diastolic blood pressure (RRd) between the different groups at different time points during the experiment. $\left(^{*}\right)$ RRd LPS iv significantly lower than Albumin $20 \%(p<0.05)$. $(<)$ RRd LPS iv significantly lower than lavage and $\mathrm{HCl}(p<0.05)$. (>) RRs $\mathrm{HCl}$ significantly lower than Albumin 20\% $(p<0.05)$

higher in each corresponding group at $\mathrm{T}=4 \mathrm{~h}$ (in comparison to $\mathrm{T}=0 \mathrm{~h}$ ), but this increase was only significant in the LPS iv group (Fig. $7 \mathrm{~A}$ and B). At the end of the experiment, the IL-6 concentration was also significantly higher in the LPS iv group when compared to the other three groups (Fig. 7 B).

Histology of the lung showed no significant differences in the mean alveolar size, alveolar wall thickness and in lung injury score (Table 2) between the four groups.

\section{Discussion}

In a comparative study, we tested four different techniques of inducing ARDS in adult ewes. Three models induced ARDs via a pulmonary injury (ARDSp), and one via sepsis due to systemic endotoxemia (ARDSexp). We investigated whether these four models would show different outcomes in terms of respiratory, cardiovascular and inflammatory parameters. The gas exchange (both oxygenation and ventilation) was severely affected with

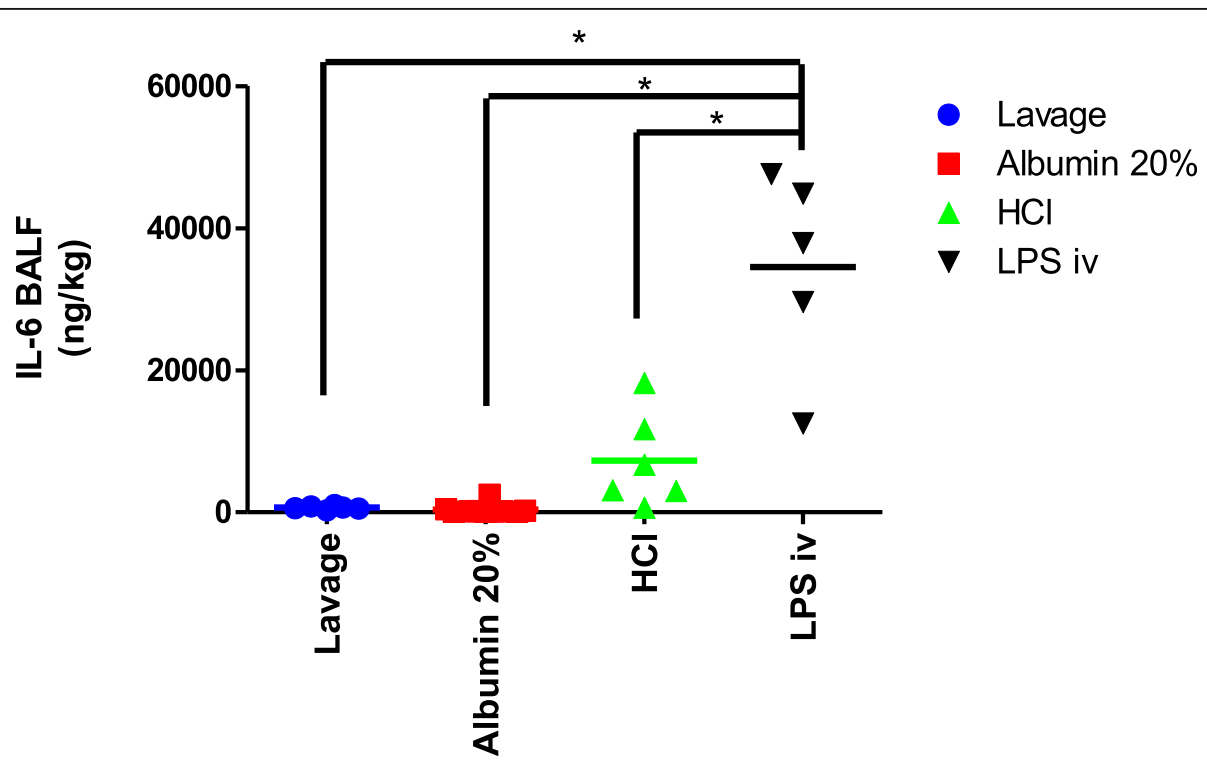

Fig. 6 Interleukin-6 (IL-6) concentration in broncho-alveolar lavage fluid (BALF) in different groups at the end of the experiment, T=4 h. The IL-6 concentration in BALF was significantly higher in the LPS iv group compared to the other three groups $(* p<0.001)$ 


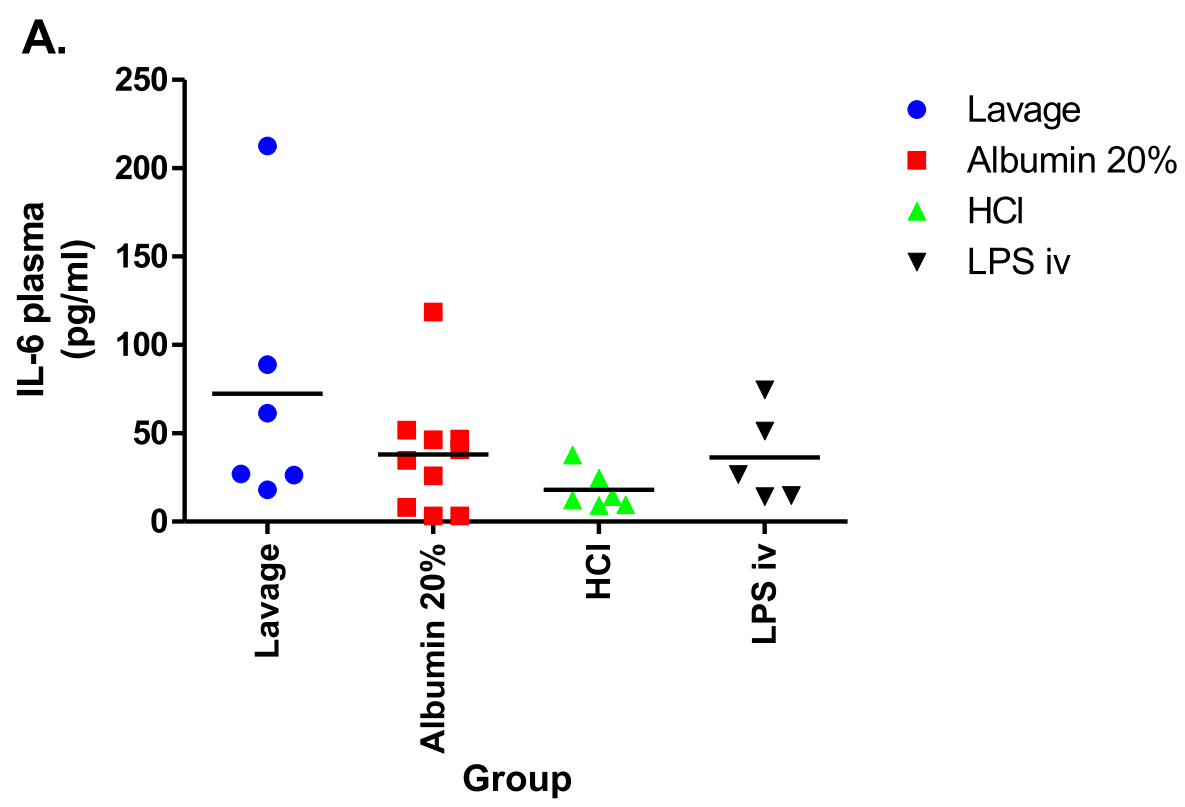

B.

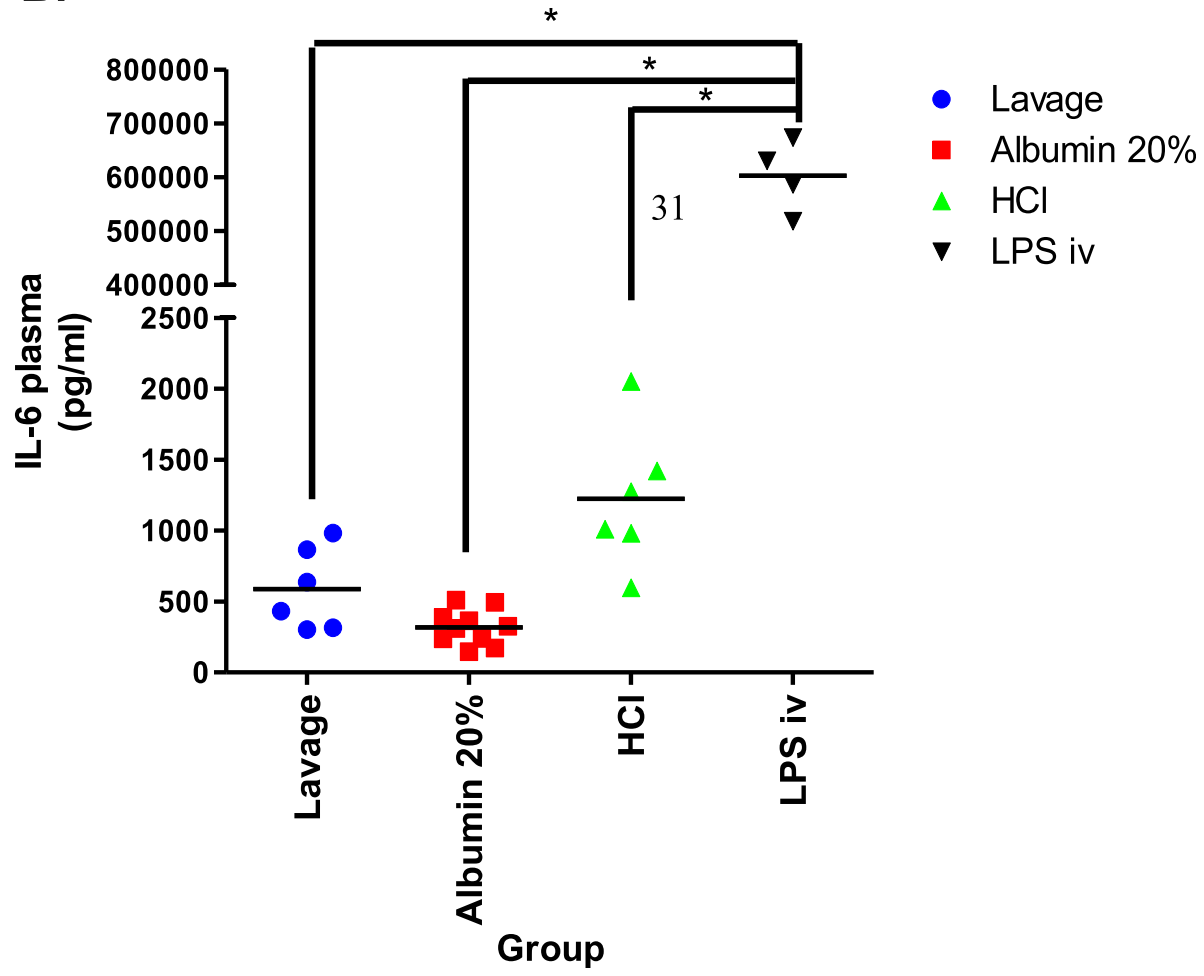

Fig. 7 Interleukin-6 (IL-6) concentration in plasma at the time point at which the criteria for ARDs was met $=0 \mathrm{~h}(\mathbf{a})$ and at the end of the experiment at $T=4 \mathrm{~h}(\mathbf{b})$. There was no difference in IL-6 concentration between all groups at the beginning (6 A). At the end of the experiment, the IL-6 concentration was significantly higher in the LPS iv group as compared to the other three groups $\left(6 \mathrm{~B}^{*}{ }^{*} p<0.001\right)$. The concentration of IL-6 in plasma was higher in each corresponding group at the end of the experiment $(T=4 \mathrm{~h})$, as compared to the time point at which the criteria for ARDs was met $(T=0 \mathrm{~h})$, but this difference was only significant in the LPS iv group (a and $\mathbf{b}$; $p<0.001)$

higher OI and lower VEI in the LPS iv group (ARDSexp) and $\mathrm{HCl}$ group (ARDSp). The circulation deteriorated in the LPS iv group over the course of the experiment, as reflected by lower diastolic blood pressure. The systemic LPS which induced ARDSexp was so severe that more than one organ system was affected. The LPS iv group 
had a higher IL-6 concentration in BALF and plasma as compared to the other three groups. These results in the LPS iv group are, however, not completely consistent with the results of the study conducted by Rosenthal et al. [12]. Rosenthal and colleagues used a pig model in which they induced ARDS using different methods. They found that broncho-alveolar hydrochloric acid instillation and lavage caused hypoxemia in pigs, while short term bolus endotoxin infusion did not result in hypoxemia [12]. However, while hypoxemia is a known effect of intravenous installation of LPS, it can take $2-4 \mathrm{~h}$ after start of infusion for this effect to become apparent [10, 14]. We therefore included the LPS iv group in the experiment after the ewes had met the criteria of ARDS, taking into account the time interval needed to induce hypoxemia. We standardized the starting time of the 4-h study period as the time point at which hypoxemia occurred, thus the time point at which the animals fulfilled the criteria for ARDS. We showed that inducing ARDS in the LPS iv group (ARDSexp) took significantly longer than it did in the other three groups. As a result, the time of the whole experiment, the time of euthanization, was longer in the LPS iv group. We have no means to assess the effect of this difference on the whole experimental procedure. The effects on the circulation in the LPS iv group in both our study and the study conducted by Rosenthal were comparable and known side-effects of the intravenous LPS model $[10,12,14]$. The LPS iv group represented ARDSexp where the injurious stimuli were not administered intrapulmonary. Despite higher systemic and pulmonary IL-6 concentrations, no differences in histological findings were detected between the LPS iv group and any of the other ARDSp groups, suggesting that the preset definition of ARDS and the short duration of the experiment resulted in a severe lung damage irrespective of the intrapulmonary or extrapulmonary origin of the injury. Taken together, the LPS iv group modeled septic shock with ARDS in a very profound and reproducible manner. The progressive deterioration in the LPS iv group was very different from the course of deterioration in the ARDSp models induced by lung lavage and intratracheal albumin $20 \%$. The OI and VEI improved over time in both groups when ARDS was induced mainly by surfactant removal or inactivation, respectively. Secretion of surfactant or production of surfactant by alveolar cells may have increased the active fraction of the surfactant pool, which may be the reason for this improvement, even while the total surfactant pool was not different.

One of the limitations of our study is the relatively short follow-up period. The focus of our study was the early, acute phase of ARDS. Mortality or long- term effects were beyond the scope of this study. We selected the (female) sheep model as a large animal model that could be used to assess the different models of ARDS and compare them to the pig models outlined earlier. All sheep were of the same gender in order to limit the effects of any potentially confounding variables. In order to mimic the human clinical situation, we did not start the study at the time of inducing ARDS, but rather when all animals had met the criteria for ARDS. Our results are in line with human studies, in which the cytokines were elevated in all forms of ARDS [28, 29]; this supports the value of our models. Nevertheless, it is difficult to translate the results of our study to the human situation. There are many differences between sheep and humans; of particular relevance to this study are the differences in poly-nuclear macrophages in the lung. Assessing these immunological differences was beyond the scope of this study.

\section{Conclusion}

In this study, we found significant differences in OI, VEI, diastolic blood pressure, and IL-6 concentration in BALF and plasma between different models of ARDS in ventilated sheep. All models were potent inducers of ARDS. We did not find injury specific pulmonary changes, but we did observe different clinical developments over the study period of $4 \mathrm{~h}$. On the one hand, clinical deterioration was present in the LPS iv group, on the other hand clinical improvement was observed in the lavage - and albumin groups. We can conclude that the different causes of ARDS resulted in the same clinical starting point but that even in short time experiments the underlying causes affect the clinical properties of the model.

\section{Abbreviations}

ARDS: Acute respiratory distress syndrome; ARDSp: Pulmonary acute respiratory distress syndrome; ARDSexp: Extra-pulmonary acute respiratory distress syndrome; AWT: Alveolar wall thickness; BALF: Broncho-alveolar lung fluid; DSPL: Disaturated phospholipids; FiO2: Oxygen fraction;

HCl: Hydrochloric acid; IL-6: Interleukin-6; IL-8: Interleukin-8;

LPS: Lipopolysaccharide; MAP: Mean alveolar pressure; MAS: Mean alveolar size; MUMC+: Maastricht University Medical Centre +; NaCl: Sodium chloride; $\mathrm{PaCO} 2$ : Arterial partial pressure of carbon dioxide; PaO2: Arterial partial pressure of oxygen; PEEP: Positive end expiratory pressure; PCV: Pressurecontrolled ventilation; PIP: Positive inspiratory pressure; Ol: Oxygenation index; RR: Respiration rate; VEl: Ventilation efficacy index; Vt: Tidal volume

\section{Acknowledgements}

Special acknowledgement to Gijs D. Vos for his contribution to the study design, interpretation of data, reading and correcting the article.

\section{Authors' contributions \\ ME: study design, preforming study, analysing data, writing article. RN: performing study, analysing data, analysing materials (BALF, plasma tissue). EJ: performing study, analysing data. DO: performing study, analysing materials (BALF, plasma, tissue). MN: performing study, analysing materials (BALF, plasma, tissue). NK: analyzing materials (BALF, plasma, tissue). LZ: study design, reading and correcting article. DW: study design, interpretation of data, reading and correcting article. BK: study design, interpretation of data, reading and correcting article. The authors have approved submitted article.}




\section{Availability of data and materials}

The datasets used and/or analysed during the current study are available from the corresponding author on reasonable request.

\section{Ethics approval and consent to participate}

The Animal Ethical Committee of the Maastricht University Medical Centre $(M U M C+)$, the Netherlands, approved the study.

\section{Consent for publication}

Not applicable.

\section{Competing interests}

The authors declare that they have no competing interests.

\section{Author details}

'Department of Pediatrics, School for Oncology and Developmental Biology - GROW, Maastricht University Medical Centre (MUMC+), P. Debyelaan 25, PO Box 5800, NL-6202, AZ, Maastricht, The Netherlands. 'Department of Pediatrics, School of Nutrition and Translational Research in Metabolism NUTRIM, Maastricht University Medical Centre (MUMC+), Maastricht, The Netherlands. ${ }^{3}$ Department of Pediatrics, School of Mental Health and Neuroscience, Maastricht University Medical Centre (MUMC+), Maastricht, The Netherlands.

\section{Received: 17 February 2020 Accepted: 28 July 2020}

Published online: 08 August 2020

\section{References}

1. The ARDS Definition Task Force. Acute respiratory distress syndrome. The Berlin definition. JAMA. 2012;307:2526-33.

2. Bernard GR, Artigas A, Brigham KL, et al. The American-European consensus conference on ARDS: definition, mechanisms, relevant outcomes and clinical trail coordination. Am J Respir Crit Care Med. 1994;149:818-24.

3. Gattinoni L, Pelosi P, Suter PM, et al. Acute respiratory distress syndrome caused by pulmonary and extrapulmonary diseas. Different syndromes? Am J Respir Crit Care Med. 1998;158:3-11.

4. Pelosi P, Caironi P, Gattinoni L. Pulmonary and extrapulmonary forms of acute respiratory distress syndrome. Semin Respir Crit Care Med. 2001;22(3): 259-68.

5. Pelosi P, D'Onofrio D, Chiumello D, et al. Pulmonary and extrapulmonary acute respiratory distress syndrome are different. Eur Respir J. 2003;22(suppl. 42):48s-56s.

6. Rocco PR, Zin WA. Pulmonary and extrapulmonary acute respiratory distress syndrome: are they different? Curr Opin Crit Care. 2005;11:10-7.

7. Pachl J, Roubik K, Waldauf $P$, et al. Normocapnic high-frequency oscillatory ventilation affects differently extrapulmonary and pulmonary forms of acute respiratory distress syndrome in adults. Physiol Res. 2006;55:15-24.

8. Rocco PRM, Pelosi P. Pulmonary and extrapulmonary acute respiratory distress syndrome: myth or reality? Curr Opin Crit Care. 2008;14:50-5.

9. Chollet-Martin S, Montravers P, Gibert C, et al. High levels of Interleukin-8 in the blood and alveolar spaces of patient with pneumonia and acute respiratory distress syndrome. Infect Immun. 1993;11:4553-9.

10. Matute-Bello G, Frevert CW, Martin TR. Animal models of acute lung injury Am J Physiol Cell Mol Physiol. 2008;295:L379-99.

11. Martin TR, Matute-Bello G. Experimental models and emerging hypotheses for acute lung injury. Crit Care Clin. 2011;27(3):735-52.

12. Rosenthal CDO, Caronia CMD, Quinn CRN, et al. A comparison among animal models of acute lung injury. Crit Care Med. 1998;26(5):912-6.

13. Reiss LK, Uhlig U, Uhlig S. Models and mechanisms of acute lung injury caused by direct insults. Eur J Cell Biol. 2012;91:590-601.

14. Ballard-Croft $C$, Wang $D$, Sumpter $L R$, et al. Large-animal models of acute respiratory distress syndrome. Ann Thorac Surg. 2012;93:1331-9.

15. Tølløfsrud PA, Medbø S, Sola AB, et al. Intratracheal albumin reduces interleukin-8 in tracheobronchial aspirates in piglets after meconium aspiration. J Perinat Med. 2004;32:78-83.

16. Lindenkov PHH, Castellheim A, Aamodt G, et al. Meconium induced IL-8 production and intratracheal albumin alleviated lung injury in newborn pigs. Ped Res. 2005:57(3):371-7.

17. Holm BA, Notter RH, Finkelstein JN. Surface property changes from interactions of albumin with natural lung surfactant and extracted lung lipids. Chem Phys Lipids. 1985;38(3):287-98.
18. Engel M, Nowacki RME, Reiss LK, et al. Comparison of recruitment manoeuvres in ventilated sheep with acute respiratory distress syndrome. Lung. 2013;191(1):77-86.

19. Engel M, Nowacki RM, Boden P, et al. The effects of dexamethasone and oxygen in ventilated adult sheep with early phase acute respiratory distress syndrome. Lung. 2015;193(1):97-103.

20. Kramer BW, Moss TJ, Willet KE, et al. Dose and time response after intraamniotic endotoxin in preterm lambs. Am J Respir Crit Care Med. 2001; 164:982-8.

21. Kramer BW, Ladenburger A, Kunzmann, et al. Intravenous lipopolysaccharide-induced pulmonary maturation and structural changes in fetal sheep. Am J Obstet Gynecol. 2009;200(2):195.e1-10.

22. Lowry OH, Rosebrough NJ, Farr AL, Randall RJ. Protein measurement with folin phenol reagent. J Biol Chem. 1951;193:265-75.

23. Mason RJ, Nellenbogen J, Clements JA. Isolation of disaturated phosphatidylcholine with osmium tetroxide. J Lipid Res. 1976;17(3):281-4.

24. Stewart JCM. Colometric determination of phospholipids with ammonium ferrothiocyanate. J Anal Biochem. 1980;104:10-4.

25. Been JV, Zoer B, Kloosterboer N, et al. Pulmonary vascular endothelial growth factor expression and desaturated phospholipid content in a chicken model of hypoxia-induced fetal growth restriction. Neonatology. 2010:97:183-9.

26. Ophelders DR, Gussenhoven R, Lammens M, et al. Neuroinflammation and structural injury of the fetal ovine brain following intra-amniotic Candida albicans exposure. J Neuroinflammation. 2016;2(13):29.

27. Matute-Bello G, Downey G, Moore BB, et al. An official American thoracic society workshop report: features and measurements of experimental acute lung injury in animals. Am J Respir Cell Mol Biol. 2011;44:725-38.

28. Schutte H, Lohmeyer J, Rosseau S, et al. Bronchoalveolar and systemic cytokine profiles in patients with ARDS, severe pneumonia and cardiogenic pulmonary oedema. Eur Respir J. 1996;9:1858-67.

29. Spadaro S, Park M, Turrini $C$, et al. Biomarkers for acute respiratory distress syndrome and prospects for personalised medicine. J Inflamm. 2019;15(16): 1.

\section{Publisher's Note}

Springer Nature remains neutral with regard to jurisdictional claims in published maps and institutional affiliations.

Ready to submit your research? Choose BMC and benefit from:

- fast, convenient online submission

- thorough peer review by experienced researchers in your field

- rapid publication on acceptance

- support for research data, including large and complex data types

- gold Open Access which fosters wider collaboration and increased citations

- maximum visibility for your research: over $100 \mathrm{M}$ website views per year

At $\mathrm{BMC}$, research is always in progress.

Learn more biomedcentral.com/submissions 